\title{
THE DARKSIDE OF IDIOSYNCRATIC DEALS: HUMANISTIC VERSUS NEOLIBERAL TRENDS AND APPLICATIONS
}

\author{
Severin Hornung, \& Thomas Höge \\ Institute of Psychology, University of Innsbruck (Austria)
}

\begin{abstract}
Theory-building on workplace flexibility is extended, based on a critical Human Resource (HR) systems framework and paradox (conflict) perspective on employee-oriented vs. capacity-oriented flexibility. Differentiated are variabilities in HR practices by: a) content (functional, temporal, spatial, numerical, financial); b) control (employer, employee); and c) creation (top-down, bottom-up). Hybrid types of bottom-up initiated and top-down authorized flexibility, idiosyncratic deals (i-deals), describe mutually beneficial, negotiated agreements on non-standard working conditions between employees and employer. If their real-world manifestations reflect idealized assumptions, however, remains obscure. Integrating institutional logics, HR systems embody values of humanistic ideals vs. neoliberal ideology: (1) individuation vs. individualism; (2) solidarity vs. competition; (3) emancipation vs. instrumentality. Reflecting these antipodes, construed ideal-type and anti-type i-deals facilitate: (a) self-actualization vs. self-reliance (needs vs. interests); (b) common good vs. tournament situations (triple-win vs. winner-take-all); (c) social transformation vs. economic rationalization (development vs. performance). In humanistic management theory, i-deals increase employee-oriented flexibility, but, in reality, risk being co-opted for economic rationalization and divisive labor-political power strategies. Antagonistic applications involve: humanization vs. rationalization goals; egalitarian vs. elitist distribution; relational vs. transactional resources; need-based vs. contribution-based authorization; procedural vs. distributive justice; supplementing vs. substituting collective HR practices. Instrumental adoption in high-performance work environments likely facilitates harmful internalizations as subjectification and self-exploitation.
\end{abstract}

Keywords: Flexibility, HR systems, idiosyncratic deals, neoliberal ideology, humanistic management.

\section{Introduction}

This contribution continues theory-building on workplace flexibility, a multifaceted and paradoxical phenomenon as complex and contradictory as the employment relationship itself (Bal \& Izak, 2020; Bessa \& Tomlinson, 2017; Cañibano, 2019). The suggested Human Resource (HR) systems framework conceptualizes flexibility as (interpersonal or intrapersonal) variable patterns in HR practices not attributable to (or going beyond) positional differences (job function, hierarchical status). Variabilities differ in: a) content (functional, temporal, spatial, numerical, financial); b) control (organizational employer vs. individual employee); and c) creation (top-down implementation, bottom-up emergence, hybrid). The framework adopts a paradox perspective, stressing conflicts of interests and tensions in employment (Glaser, Hornung, \& Höge, 2019). Underlying employee-oriented vs. capacity-oriented flexibility, conflicts incorporate employee autonomy (over working conditions) vs. adaptivity (complying with flexibility requirements), respectively, as employer authority (over terms of employment) vs. acceptance (of flexibility constraints). Dialectic interdependencies connect functional, temporal, spatial, numerical, and financial flexibility content on the organizational level with employee influence over important aspects of their working life, demanding adaptivity to changing work tasks, working times, work locations, hours employed, and take-home pay. This inverse relationship of antagonistic tensions between employee and employer flexibility means that increases or decreases in one diminish or open up degrees of freedom for the other (Bal \& Izak, 2020). Embedded in the flexibility framework is the concept of idiosyncratic deals (i-deals), defined as mutually beneficial voluntary agreements on non-standard working conditions, negotiated between individual employees and employer (supervisors, managers, HR). Authorizing personalized terms, such as customized work schedules, job tasks, learning opportunities or career support, i-deals represent hybrid types of bottom-up (employee) initiated and top-down (employer) authorized personalized workplace flexibility (Hornung, Glaser, \& Rousseau, 2018). A related construct, job crafting captures unauthorized modifications employees implement to 
improve their job designs and work experiences. Both are advocated as win-win" situations, increasing flexibility of organizations to change and motivate high-performance workforces by aligning jobs with employee needs and preferences, capitalizing on "high road" employment relationships. The extent to which real-world manifestations reflect idealized assumptions, however, is unclear. Based on previous research, theory development is offered regarding prerequisites and boundary conditions of mutually beneficial workplace flexibility in the context of the observed neoliberal reconfiguration of work organizations (Hornung \& Höge, 2019). To reconcile assumptions on i-deals (mutual benefits) with the paradox HR framework (conflicts of interest), institutional (managerial) logics are included as meta-dimensions of HR systems, capturing higher-order values of humanistic ideals vs. neoliberal ideology: (1) individuation vs. individualism; (2) solidarity vs. competition; (3) emancipation vs. instrumentality. These three ideological antipodes offer an analytic grid to contrast the humanistic ideal of employee-oriented management practices contributing to wellbeing, health, and development, with anti-type arrangements employed as labor political power strategy within agendas of austerity, precarization, and performance pressure.

\section{Flexibility as neoliberal ideology}

Neoliberalism, as used here, stands for hegemony of economic interests, the "totalization" of money, markets, and management, creating excessive wealth for a small minority, and various degrees of austerity, poverty, and environmental destruction for the rest (Bal \& Dóci, 2018; Beattie, 2019; Hornung \& Höge, 2019). Recent debates in organizational scholarship portray neoliberal ideology as a matrix of political, social, and "fantasmatic" (subconscious) logics, orienting workplace practices and research towards individualism, competition, and instrumentality. Individualism demands self-reliance, holding individuals responsible for their life situation, wealth, health and happiness, education, and employment, without consideration of societal conditions (structural inequality), eroding collective pursuit of interests (unions, welfare), interpersonal relationships, and support. Competition on "free" markets is deemed imperative for progress and allocation of resources. In all domains of society, markets should determine values of goods and services; among the most versatile commodities are "human resources". Instrumentality refers to "objectification" of humans as "resources", exploited by cost-benefit, means-end or input-output calculations, absorbing their time, activities, and existence, for profit and economic goals. These tendencies manifest as employee self-reliance instead of employment security, competition on internal and external labor markets, and multitudes of interventions, from supervision and performance assessment, motivation and training, to restructuring and change management, all aimed towards objectives (profit, performance) that do not primarily benefit those "instrumentalized" for these purposes.

\section{Flexibility as humanistic ideal}

Humanistic ideas of individuation, solidarity, and emancipation are suggested as antagonistic counter-principles to neoliberal dogmas and utilization strategies (Bal \& Dóci, 2018; Hornung \& Höge, 2019). Antipode to neoliberal individualism, individuation represents the humanistic ideal of personal development, growth, and (self-)insight. Considered central to the human condition, individuation is inherent in imageries, such as existentially becoming "who one is meant to be", becoming a fully developed or fully functioning person, self-actualization, following a calling, finding meaning, wisdom or insight. As social logic applied to workplaces, individuation converges with self-actualization, including discretion to autonomously pursue personally significant tasks satisfying higher-order needs for growth, prosocial impact, and transcendence. Antipode to competition, solidarity emphasizes collaboration, cohesion, and shared use of resources. Solidarity is directed at those in a similar or worse situation as oneself, facing struggles, adverse conditions or injustice. As a social logic, solidarity orients workplaces towards structural participation and models of common good economy and organizing (reducing differences in status, pay, and privileges). The humanistic ideal of emancipation has multiple layers of meanings, referring to "liberation" or attaining freedom, by overcoming exploitative, unjust, or limiting (coercive, manipulative) power-structures and power-dependence relationships (Huault, Perret, \& Spicer, 2014). Mostly abandoning this macro-emancipatory meaning, the organizational literature has highlighted micro-emancipatory actions, through which employees increase freedom at work, for instance, by resisting pressure and avoiding control by management, or self-actualizing by crafting and creating meaning and fulfillment in their work activities Social logics of emancipation seek to maximize employee autonomy and influence, self-determination, self-organization, and participation, including semi-autonomous work groups and organizational democracy. This counter-model to neoliberal ideology was framed as organizing for social transformation versus economic rationalization. 


\section{Applications of ideological antipodes}

Reflecting ideological antipodes (individuation vs. individualism; solidarity vs. competition; emancipation vs. instrumentality), construed ideal-type and anti-type i-deals are theorized to diametrically orient flexible work arrangements towards: (a) self-actualization vs. self-reliance (needs vs. interests); (b) common good vs. tournament situations (triple-win vs. winner-take-all); (c) social transformation vs. economic rationalization (development vs. performance). Evaluation criteria for opposing implementation strategies of (neoliberal) individualized and humanistic (personalized) work arrangements include: a) objectives (humanization vs. rationalization goals); b) distribution (egalitarian vs. elitist distribution); c) content (relational vs. transactional resources); d) basis of authorization (need-based vs. contribution-based); e) organizational justice principles (procedural vs. distributive fairness); and f) work system embeddedness (supplementing vs. substituting collective HR practices and benefits). Under theoretical preconditions, i-deals introduce employee-oriented flexibility as a humanistic management practice, but risk being misused for economic rationalization and divisive labor-political power strategies (Hornung \& Höge, 2019; Weiskopf \& Loacker, 2006). Instrumental adoption in high-performance work systems further internalizes tensions as subjectification, underlying self-exploitation, marketing orientation, and governmentality. Recommended are refined conceptualizations, measures, and more comprehensive (multi-source, multi-method) research designs, to clearly differentiate i-deals from neoliberal look-alikes.

\section{Conclusion}

There is ongoing need to clarify the ambiguous, often misrepresented phenomenon of workplace flexibility, particularly, idiosyncratic deals. Deconstructing implied logics, applications, and ideal-types, offers critical angles for studying flexibility and individualization. Humanistic conceptions of idiosyncratic deals reflect employee-oriented workplace flexibility, but within a neoliberal paradigm they may provide vehicles for economic rationalization and divisive labor-political power tactics. Aggravating are behavioral forces in high-performance work systems, where internalized tensions emerge as self-exploitation, marketing orientation, and psychological governance. Following a paradox perspective, promoting employee-oriented flexibility means containing capacity-oriented flexibility. Application of ideological antipodes to evaluate workplace flexibility illustrates the usefulness of this model.

\section{References}

Bal, P. M., \& Dóci, E. (2018). Neoliberal ideology in work and organizational psychology. European Journal of Work and Organizational Psychology, 27, 536-548. doi:10.1080/1359432X.2018.1449108

Bal, P. M., \& Hornung, S. (2019). Individualization of work: From psychological contracts to ideological deals. In Y. Griep \& C. L. Cooper (Eds.), Handbook of research on the psychological contract at work (pp. 143-163). Cheltenham, UK: Edward Elgar.

Bal, P. M., \& Izak, M. (2020). Paradigms of flexibility: a systematic review of research on workplace flexibility. European Management Review, in press. doi:10.1111/emre.12423

Beattie, P. (2019). The road to psychopathology: Neoliberalism and the human mind. Journal of Social Issues, 75, 89-112. doi:10.1111/josi.12304

Bessa, I., \& Tomlinson, J. (2017). Established, accelerated and emergent themes in flexible work research. Journal of Industrial Relations, 59, 153-169. doi:10.1177/0022185616671541

Cañibano, A. (2019). Workplace flexibility as a paradoxical phenomenon: Exploring employee experiences. Human Relations, 72, 444-470. doi:10.1177/0018726718769716

Glaser, J., Hornung, S., \& Höge, T. (2019). Organizational tensions, paradoxes, and contradictory demands in flexible work systems. Journal Psychologie des Alltagshandelns / Psychology of Everyday Activity, 12(2), 21-32.

Hornung, S., \& Höge, T. (2019). Humanization, rationalization or subjectification of work? Employee-oriented flexibility between i-deals and ideology in the neoliberal era. Business \& Management Studies: An International Journal, 7, 3090-3119. doi:10.15295/bmij.v7i5.1384

Hornung, S., Glaser, J., \& Rousseau, D. M. (2018). Idiosyncratic deals at work: A research summary. Journal Psychologie des Alltagshandelns / Psychology of Everyday Activity, 11(1), 36-46.

Huault, I., Perret, V., \& Spicer, A. (2014). Beyond macro-and micro-emancipation: Rethinking emancipation in organization studies. Organization, 21, 22-49. doi:10.1177/1350508412461292

Weiskopf, R. \& Loacker, B. (2006). "A snake's coils are even more intricate than a mole's burrow." Individualization and subjectification in post-disciplinary regimes of work. Management Revue, 17, 395-419. doi:10.5771/0935-9915-2006-4-395 